\title{
Subconjunctival emphysema due to trauma by compressed air tube
}

\author{
YORAM BIGER AND CHAIM ABULAFIA \\ From the Department of Ophthalmology, Rebecca Sieff Government Hospital, Safed, Israel
}

SUMMARY A rare case of subconjunctival emphysema due to trauma by compressed air tube, without fracture in the orbit, and its treatment are described.

An orbital fracture is a common complication of trauma to the eye. One of the classical signs of such a fracture is the presence of subconjunctival emphysema as a consequence of direct passage of air from the nasal sinuses to the orbit. ${ }^{12}$ We have treated a patient who suffered from subconjunctival emphysema after trauma due to direct penetration of compressed air to the orbit, without orbital fracture. We believe this type of ophthalmic injury has not been described previously.

\section{Case report}

A 29-year-old male was wounded in his left eye while working in a metal factory. He was cleaning himself from metal dust, using a compressed air tube, at $50 \mathrm{psi}\left(3 \cdot 5 \mathrm{~kg} / \mathrm{cm}^{2}\right.$, approx. 3 atmospheres), when his left upper eyelid was everted by the pressure and the

Correspondence to Dr Y Biger.

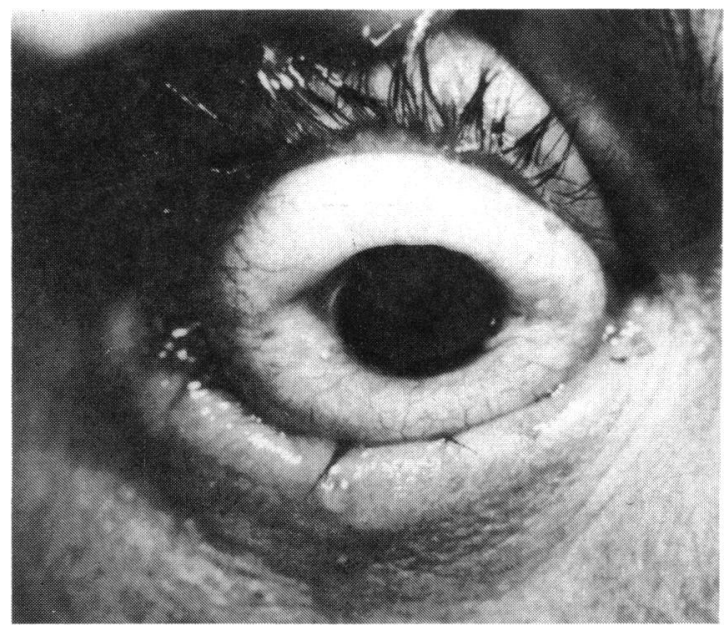

Fig. 1 Severe subconjuctival emphysema. air stream wounded his eye. On examination the visual acuity was normal in both eyes. The left eye had a large subconjunctival emphysema (Fig. 1), with a small metal foreign body in the cornea. The intraocular pressure was $28 \mathrm{mmHg}$ by applanation tonometry, but the inner parts were normal. An $x$-ray showed that air had collected around the cornea (Fig. 2) without an orbital fracture.

Early treatment included the removal of the foreign body from the cornea and the bandaging of the eye with antibiotic ointment. The following day most of the air in the upper part was absorbed, while the emphysema persisted in the lower conjunctiva and prevented lid closure. An incision was made in the conjunctiva to release the air. Three days later the patient had completely recovered.

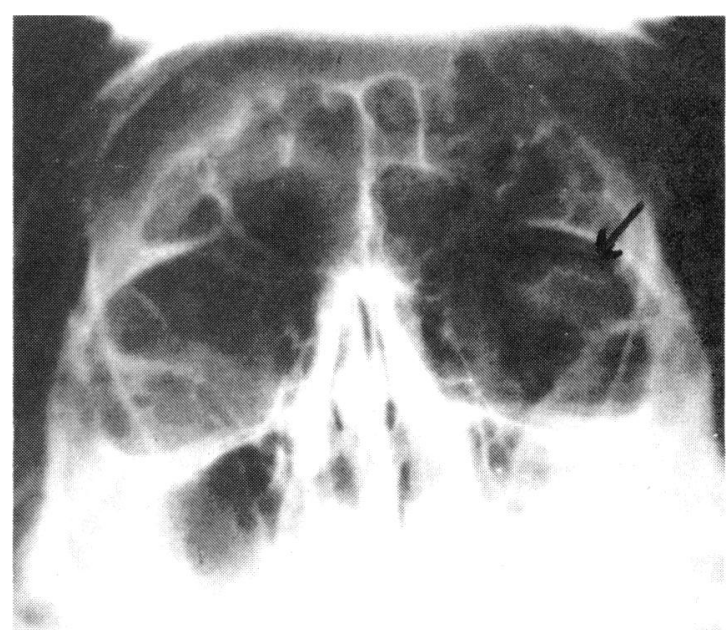

Fig. 2 Subconjunctival emphysema (arrow) in the form of a ring around the cornea. There is no sign of an orbital fracture. 


\section{Discussion}

This rare type of trauma resulted in emphysema by direct penetration of air through the thin conjunctiva. We believe that the high pressure created some microscopic tears in the conjunctiva, but these tears closed immediately afterwards, resulting in emphysema. The air was spontaneously absorbed in a few days, but the patient's inability to close the lids justified surgical drainage.

In the classical ophthalmological textbooks the presence of a subconjunctival emphysema after orbital trauma is considered to be pathognomonic of an orbital fracture. ${ }^{12}$ The only information dealing with subconjunctival emphysema without an orbital fracture is to be found in an article on deep diving. ${ }^{3}$

\section{References}

1 Duane TD. Clinical ophthalmology. Philadelphia: Harper and Row, 1984: 2: 21.

2 Duke-Elder S. System of ophthalmology. St Louis: Mosby, 1972; 14: 291-4.

3 Bielicka W, Bicganowski L. Subconjunctival emphysema in a skin-diver. Wias Lek 1981; 34: 1295-8.

Accepted for publication 28 June 1985. 